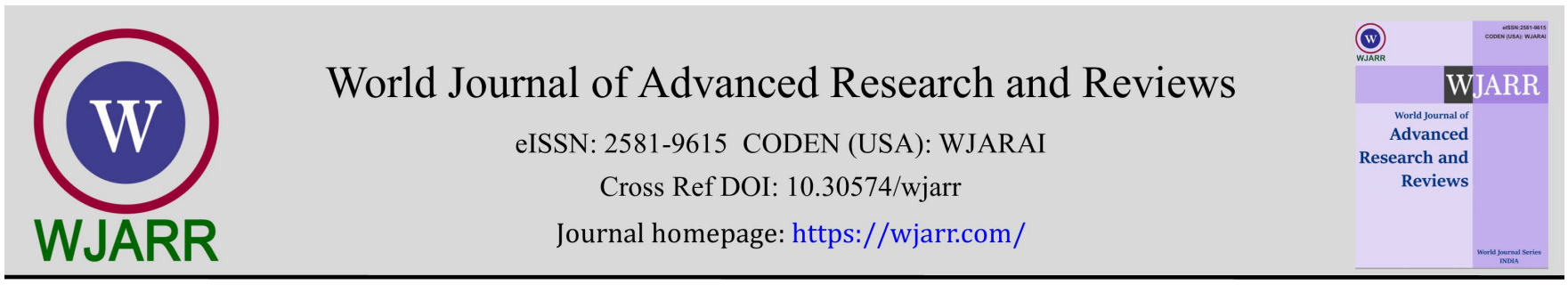

(RESEARCH ARTICLE)

Check for updates

\title{
Estimation of radioelements concentration in Sokoto Basin for geothermal energy studies using airborne radiometric data
}

\author{
Ndidiamaka Nchedo Eluwa 1, 2, ${ }^{*}$, Alexander Iheanyichukwu Opara 2, Chikwendu Njoku Okereke 2, John \\ Chibuzo Eluwa ${ }^{3}$ and Rock Mkpuma Onwe ${ }^{1}$
}

${ }^{1}$ Alex Ekwueme Federal University Ndufu Alike, Ebonyi State Nigeria.

${ }^{2}$ Federal University of Technology, Owerri Imo State Nigeria.

${ }^{3}$ National Root and Crops Research Institute, Umudike Abia State, Nigeria.

World Journal of Advanced Research and Reviews, 2021, 12(01), 315-325

Publication history: Received on 09 September 2021; revised on 13 October 2021; accepted on 15 October 2021

Article DOI: https://doi.org/10.30574/wjarr.2021.12.1.0514

\begin{abstract}
High resolution aero-radiometric data of Sokoto basin Northwestern, Nigeria were used in this research work. The location of the basin is between latitude $11^{\circ} 30^{\mathrm{I}}$ to $13^{\circ} 30^{\mathrm{I}} \mathrm{E}$ and longitude $4^{\circ} 30^{\mathrm{I}}$ to $6^{\circ} 30^{\mathrm{I}} \mathrm{N}$. Sixteen (16) sheets of high resolution of airborne radiometric data were used to obtain the concentration of Potassium (K), Uranium (U) and Thorium (Th) respectively in the area of interest. The data were gridded and analyzed using Geosoft software. The result of the analysis revealed that potassium concentration is between $-0.577935 \%$ to $7.34347 \%$ with an average of $3.3827 \%$. The Thorium concentration values ranged from $-3.81541 \mathrm{ppm}$ to $91.9404 \mathrm{ppm}$ with an average of $44.0624 \mathrm{ppm}$. The Uranium concentration revealed values from $-4.44524 \mathrm{ppm}$ to $46.1767 \mathrm{ppm}$ with an average of $20.86572 \mathrm{ppm}$. The ratio of potassium and equivalent thorium (K/eTh) indicated values between $-8.69847 \% / \mathrm{ppm}$ to $39.567 \% / \mathrm{ppm}$ and ratio of equivalent uranium and equivalent thorium (eU/eTh) revealed values between $-412.181 \mathrm{ppm}$ to $99.4613 \mathrm{ppm}$. The ternary diagram of the radiometric data showed that the south and southeastern regions of the study area have high radioactive mineral concentration above the average normal value of radioactive minerals in a natural environment and radioactive minerals are good source of geothermal energy. The results obtained has shown that the basin has geothermal potential which can cause non productivity of hydrocarbon in the area of interest and the research area can be recommended for geothermal energy resource to compliment the electric power supply in the nation.
\end{abstract}

Keywords: Geothermal energy; Airborne radiometric; Radioactive minerals; Potassium; Uranium; Thorium; Hydrocarbon.

\section{Introduction}

In Nigeria, geothermal energy resources are desirable in the generation of electricity. This alternative energy resource will be a good relief to the current electricity challenge. The study of geothermal activities of the study area, showing the manifestation of heat will be an attractive and cheaper alternative energy source in the country [1][2][3]. It is very important for the nation to engage and improve alternative renewable energy resources such as geothermal energy since there are evidences of geothermal energy potentials on the surface such as warm and hot springs both on the basement and sedimentary areas within the country to compliment hydrocarbon.

Olumide et al.,[4] said that Hydrocarbon extraction in Niger-Delta which is practiced extensively now is predicted to be exhaust in 2040. The need for renewable alternative sources of energy for use in the country became very necessary due to epileptic power supply in the country. The National Renewable Energy and Energy Efficiency (NREEE) Policy

\footnotetext{
*Corresponding author: Eluwa Ndidiamaka Nchedo; E-mail:ndidiamakaeluwa@gmail.com

Alex Ekwueme Federal University Ndufu Alike, Ebonyi State Nigeria. 
articulates for 30\% renewable energy by 2030 for electricity generation. Kenya and Ethiopia have been using geothermal energy resources for electric power generation over $1000 \mathrm{~mW}$.

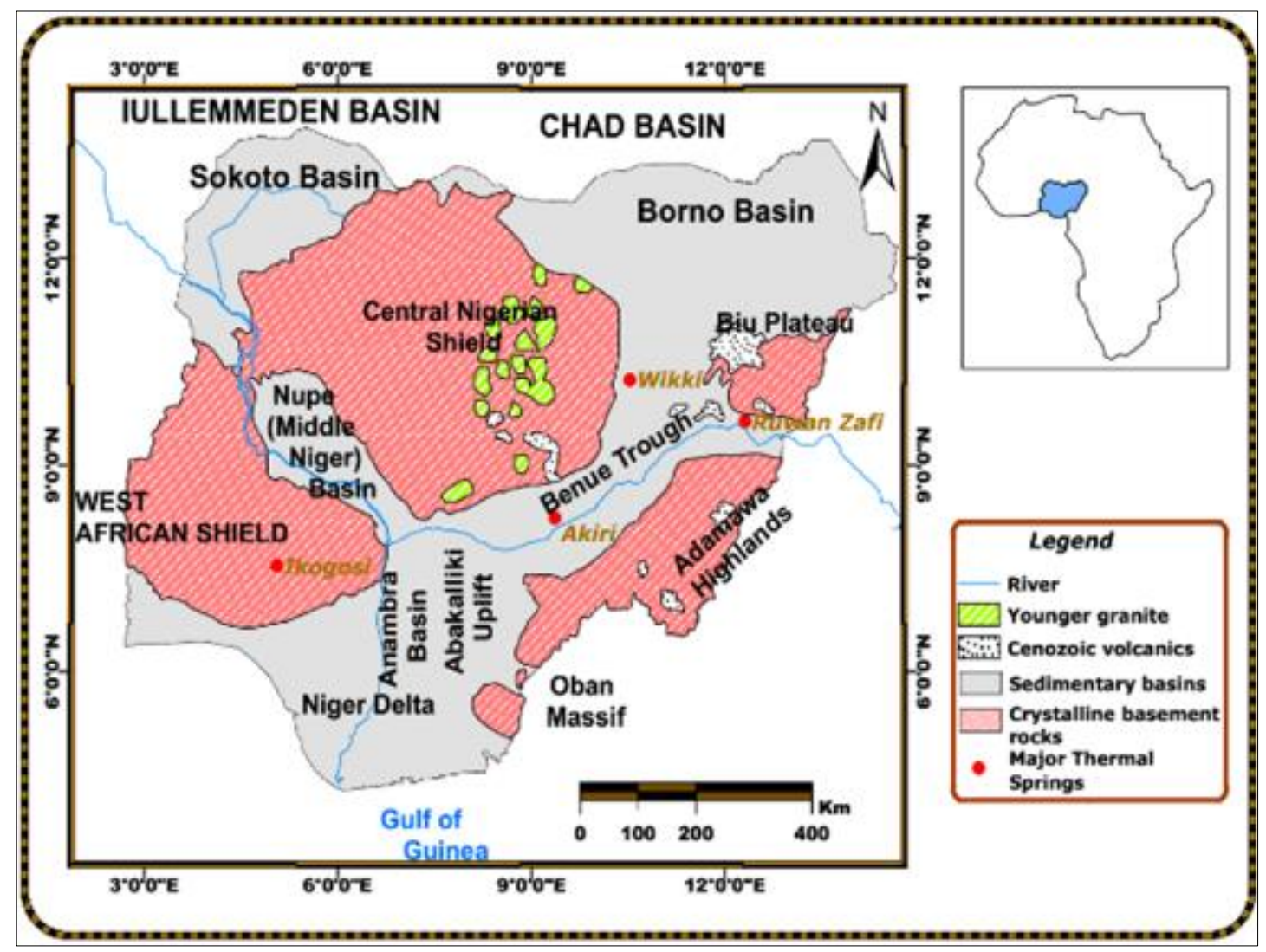

Figure 1 Major Hot Springs in Nigeria and Their Locations with Geologic Setting

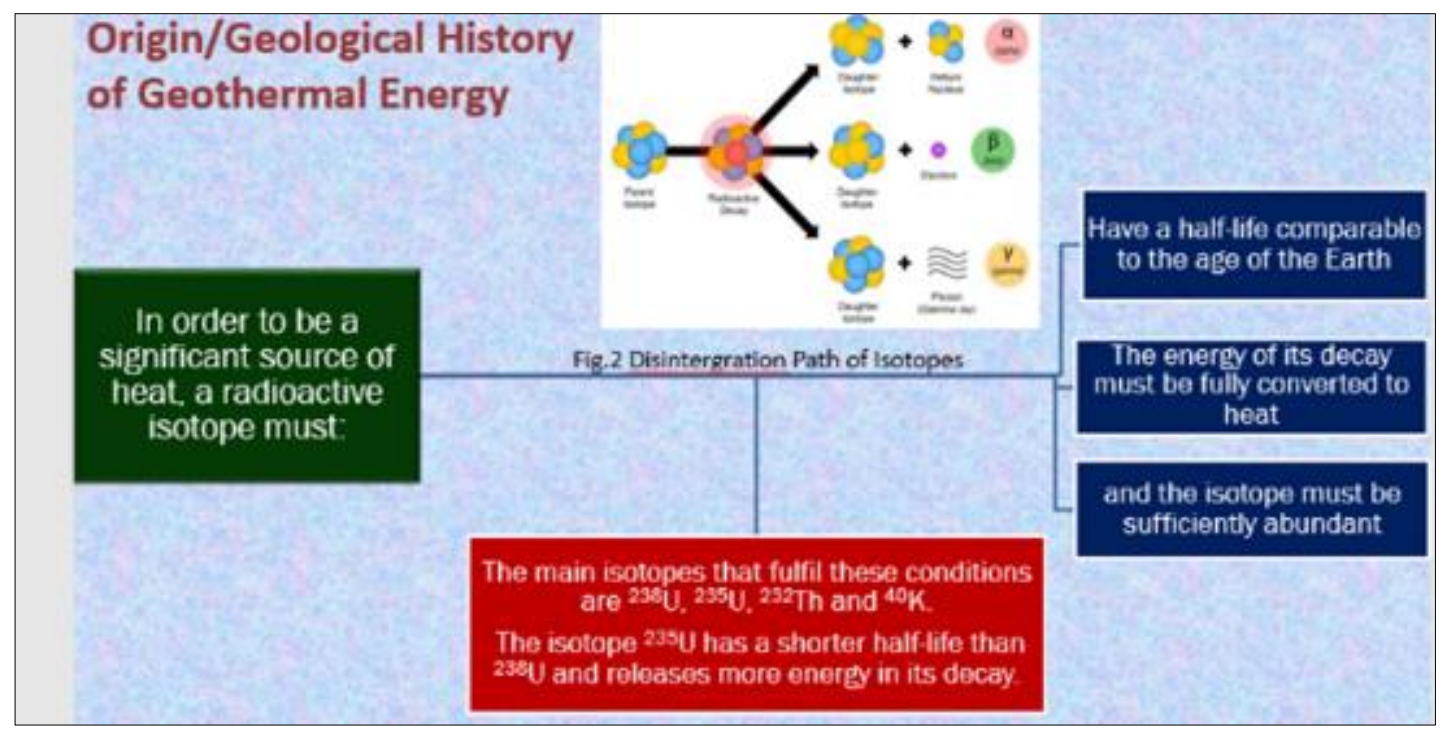

Figure 2 Disintergration path of lsotopes

Aero-Radiometric survey is one of the most economic technique used in geophysical survey to understand any relatively inaccessible/unexplored zones. The method can give information on the structural trends and volcanic rocks occurrence within sedimentary basins. Advance techniques made recently in acquisition of high resolution aeroradiometric data, emphasizing on exploration of minerals, where the minerals of interest revealed considerably radiometric anomalies [5]. 
Radiometric investigations reveal natural radiometric anomalies/emanations known as gamma rays from soils and rocks. At least twenty (20) elements which occurred naturally are said to be radioactive elements [6]. Gamma radiation are detected from earth materials which comes from natural decay product of elements such as potassium, uranium and thorium. Many other natural occurring elements have radioactive isotopes but it is only uranium, thorium and potassium decay series that have radioactive isotopes that produces gamma rays of sufficient intensities and energies to be recorded by gamma ray spectrometer. The reason is because the three (3) elements (potassium, uranium and thorium) are relatively abundance in the natural environment.

Average crustal abundances of these elements quoted are in the range 2-2.5\% of K, 2-3 ppm of $\mathrm{U}$ and 8-12 ppm of Th. Air-borne radiometric survey, when used in appropriate areas as a reconnaissance method for geologic mapping and prospecting, the benefit and cost ratio is nearly as good as aeromagnetic surveying using magnetometer [5]. Analysis of radiometric data will help to determine the relative abundance of natural radioactive elements $(\mathrm{K}, \mathrm{U}, \mathrm{Th})$ in the rock types.

The nuclear intensities of radiations in any given terrestrial environment are related generally to the abundances of radioactive minerals in the basement rocks and soils of that area. [5][7][8][9]. It is also used in estimation of radioactive minerals in sedimentary and basement rocks. Radiometric method has been used extensively for geologic mapping of an area for rock formations associated with radioactive minerals. Results obtained from the aero-radiometric measurements can be considered to be a representative of radiometric characteristics of basement rocks under the soil cover because soil cover were generally derived from basement rock weathering secondly, there are some degrees of mixing over lengthen geologic period of time between soil and subsurface soil layers.

Spectrometer gamma ray techniques have been used widely in obtaining measurements of radioactive elements (K, $\mathrm{U}$ and Th) in soils and rocks (as seen in Adams \& Gasparini [10], Iyengar et al., [11], Mohanty et al., [12]). It has been also used to map area extent of rock formations in association with radioactive minerals. Examples of such studies carried out in Brazil include the works of Blum et al., [13], [12]. For ground measurements of spectrometer gamma radiation, the data obtained gives information on the relative abundances of radioactive minerals in the surface (top soil) layers with thicknesses of less than $40 \mathrm{~cm}$. Nevertheless, the results obtained from aero-radiometric measurements are representing radiometric characteristics of the basement rock. The application of radioactivity in geosciences is based on knowledge of the physical properties of radiation sources and the ability to detect these sources through the analysis of remotely sensed data. Few benefits that can expect from the interpretation of radiometric surveys include: i) In geologic reconnaissance survey, changes in lithology of the rock samples are mostly accompanied with changes in the concentration of the three radioactive minerals uranium, potassium and thorium. ii) Radioactive elements concentration variations may possibly indicate primary geologic processes like mineralization solutions or metamorphic process. iii) These variations may also be characterized as secondary geologic processes such as leaching and supergene alteration. iv) Radiometric investigations have the ability to directly detect the presence of uranium deposit. v) Radiometric surveys can also help in the location of some intrusive relating mineral deposits.

Uranium concentration is estimated as "equivalent uranium" (eU), this is based on the assumption of equilibrium condition. Thorium concentration is also estimated as "equivalent thorium" (eTh), this is based on the account that thorium decay series mostly always in equilibrium. A ternary radiometric data map is a composite colour image gotten by regulating the blue, green and red colors of the display device or magenta, yellow and cyan dyes of the printer in agreement to the radiometric elements concentration values of the $\mathrm{U}$, Th, Kand TC grids. The three colours blue, green and red are representing uranium, thorium and potassium respectively, it is standard colours for displaying gamma ray spectrometric information. U-channel is the noisiest channel and blue color is normally used in displaying the U-channel, the human eye is not too sensitive to the disparities in the blue intensity. Areas of low radioactivity and consequently low signal to noise ratios, can be masked by setting a threshold on the total count grid. This set aside more color space and guarantees a good color intensification for the other radioelements.

According to Wilford et al., [9]; [5] Sum-normalization can be used to compute relative concentrations of K, Th and U prior to imaging as follows:

$$
\begin{aligned}
& \mathrm{K}_{\mathrm{n}}=\mathrm{K} / \mathrm{K}+\mathrm{U}+\mathrm{Th} \ldots \ldots \ldots \ldots \ldots \ldots \ldots \ldots \ldots \\
& \mathrm{U}_{\mathrm{N}}=\mathrm{U} / \mathrm{K}+\mathrm{U}+\mathrm{Th} \ldots \ldots \ldots \ldots \ldots \ldots \ldots \ldots \ldots \ldots \ldots \ldots \ldots \ldots \\
& \mathrm{Th}_{\mathrm{n}}=\mathrm{Th} / \mathrm{K}+\mathrm{U}+\mathrm{Th} \ldots \ldots \ldots \ldots \ldots \ldots \ldots \ldots \ldots
\end{aligned}
$$


This converts the radioelement concentrations to relative abundance. Sum-normalization can be useful to reduce the effects of the attenuation of gamma rays by vegetation or soil moisture.

Continental heat flow mostly originated from the disintegration of radioactive isotopes in the earth's crust, areas with high heat flow are attributed to area with high radioactive isotope concentration [14].

Radiogenic Heat Production (RHP), $\mathrm{H}\left(\mu \mathrm{W} / \mathrm{m}^{3}\right.$ ) is related to the decay of primary radioactive isotopes ${ }^{232} \mathrm{Th},{ }^{238} \mathrm{U}$ and ${ }^{40} \mathrm{~K}$ and can be estimated based on the rate of concentration of the elements respectively [14] [15] through Equation 4:

$$
\mathrm{H}=\rho\left(9.52 \mathrm{C}_{\mathrm{U}}+2.56 \mathrm{C}_{\mathrm{Th}}+3.48 \mathrm{C}_{\mathrm{K}}\right) 10^{-5}
$$
4

Where $\rho$ is the density of the rock, $C_{U}$ is the concentrations in uranium, $C_{T h}$ is the concentration in thorium and $C_{K}$ is the concentration in potassium. They are given in weight/parts per million and weight percent for potassium $\left(\mathrm{C}_{\mathrm{K}}\right)$ respectively.

Heat flow lies analytically on radioactive heat generation in the earth's crust. The two primary effects are; that continental heat flow is proportional to the earth's crustal surface radioactivity in a given region and decreases with time after the preceding great tectonic event. Heat flow is considered as a continuous function inside the earth; particularly, it will be the same on both sides of the boundary separating the crust from the mantle [16]. Plot of heat flow and heat generation rate from radioactive rocks produces a linear distribution segments which may be fitted in a linear equation of the form:

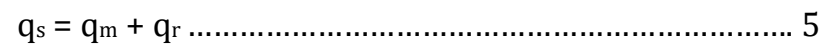

Where $\mathrm{q}_{\mathrm{s}}=$ crustal surface heat flow, $\mathrm{q}_{\mathrm{m}}=$ mantle heat flow (heat flow into the base of the crust). The total contribution of heat production in the crust to the surface heat flow $\mathrm{q}_{\mathrm{r}}$ is therefore,

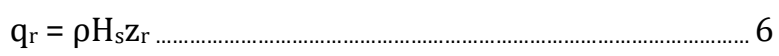

Where

$\rho=$ density of the crust

$\mathrm{H}_{\mathrm{s}}=$ heat production measured in rocks collected at the surface

$\mathrm{Zr}_{\mathrm{r}}$ can be explained as the 'equivalent depth expanse of heat production,' That is, the degree to which the heat production sustained at the earth's surface $\left(\mathrm{H}_{\mathrm{s}}\right)$ increases to depth, if distribution models are considered for radioactivity in the earth's crust and proportion of heat production [5]. Master \& Constable [16] have presumed Zr to be much less than the thickness of the continental earth's crust. Naturally, it is clear that radioactivity isn't constant in the earth's crust down to $\mathrm{Zr}$ and below, but the model has shown a fair indication of the degree of heat flow at the surface to be due to radioactivity.

\section{Methodology}

Airborne radiometric data sets were acquired including measurement of the Degree of gamma radiation emitted by radioelements; Thorium, Uranium and Potassium. Ternary diagram and ratio maps were obtained. The values of primary radiometric data of airborne surveys were in the units of part per million (ppm). These were transformed into values of relative abundances of $U$, Th and $K$ using conversion factors specific to instrumentation. Sixteen sheets were used in the analysis. Radiometric data obtained were all analyzed to produce and correlate the results with geologic attributes of the study area. The results of the gamma ray spectrometric techniques have been used widely as supplementary tools in geological mapping.

The potassium image was developed to identify regions of strong potassium concentration. Thorium is usually considered as a stable element which does not move easily. However, several deposits of gold depict increases in potassium and thorium which suggest that thorium was moved during hydrothermal activities [9] [17].

Reduction in thorium and increase in potassium shows a signs of alteration for most deposits of ore. This discovery and other reasons led in the development of the thorium (Th) image map. The uranium image especially ratio map of 
uranium and potassium $(\mathrm{U} / \mathrm{K})$ shows good definition in mapping the granitoid rocks which show low uranium but high potassium concentration.

The composite image map of the radioelements was presented in a single map, showing the concentration of the three radioelements $\mathrm{Th}, \mathrm{U}$ and $\mathrm{K}$. This image map indicates the extent of the concentration of the radioelements based on color variations which is attributed to the lithological differences. The radioactive element maps helped to map out zones where a particular radioelement has a higher concentration and also the trend [12] [17].

Uranium, potassium and thorium were represented with blue, red and green respectively in generating the ternary map. In order to minimize the poor signal-to-noise ratio especially in the uranium concentration the blue color was used. The maps discussed in the study were generated with the relative intensities of color to represent slight differences caused by the rock types. To enhance the contrast of the histogram of thorium, potassium and uranium, a histogram was used to present the finest color differences prior to generating the ternary map.

Nevertheless, for this research work, the ternary image generated demonstrated a better outcome.

In order to get rid of lithological differences and variations caused due to soil moisture, non-planar nature of the host rock and errors related with altitude correction, ratio images were as well produced. According to [12], lithological variations have a tendency to be removed because radioelement amounts normal change as lithology change. For example, eU/eTh and $\mathrm{K} / \mathrm{eTh}$ ratios were created for locating the areas where relative amount of uranium and potassium are strong.

\section{Results and Interpretation}

The radiometric data were gridded and analyzed to develop the Total Count, Uranium, Thorium and Potassium maps respectively, in order to reveal the surface distribution and delineate surface lineaments of these radioelements. Also, the radiometric data was used to produce K/Th ratio map and U/Th ratio map and these help to map geothermal alteration zones. A ternary map was created by combining the three (3) radioelements concentration in the Red-GreenBlue (RGB) colours.

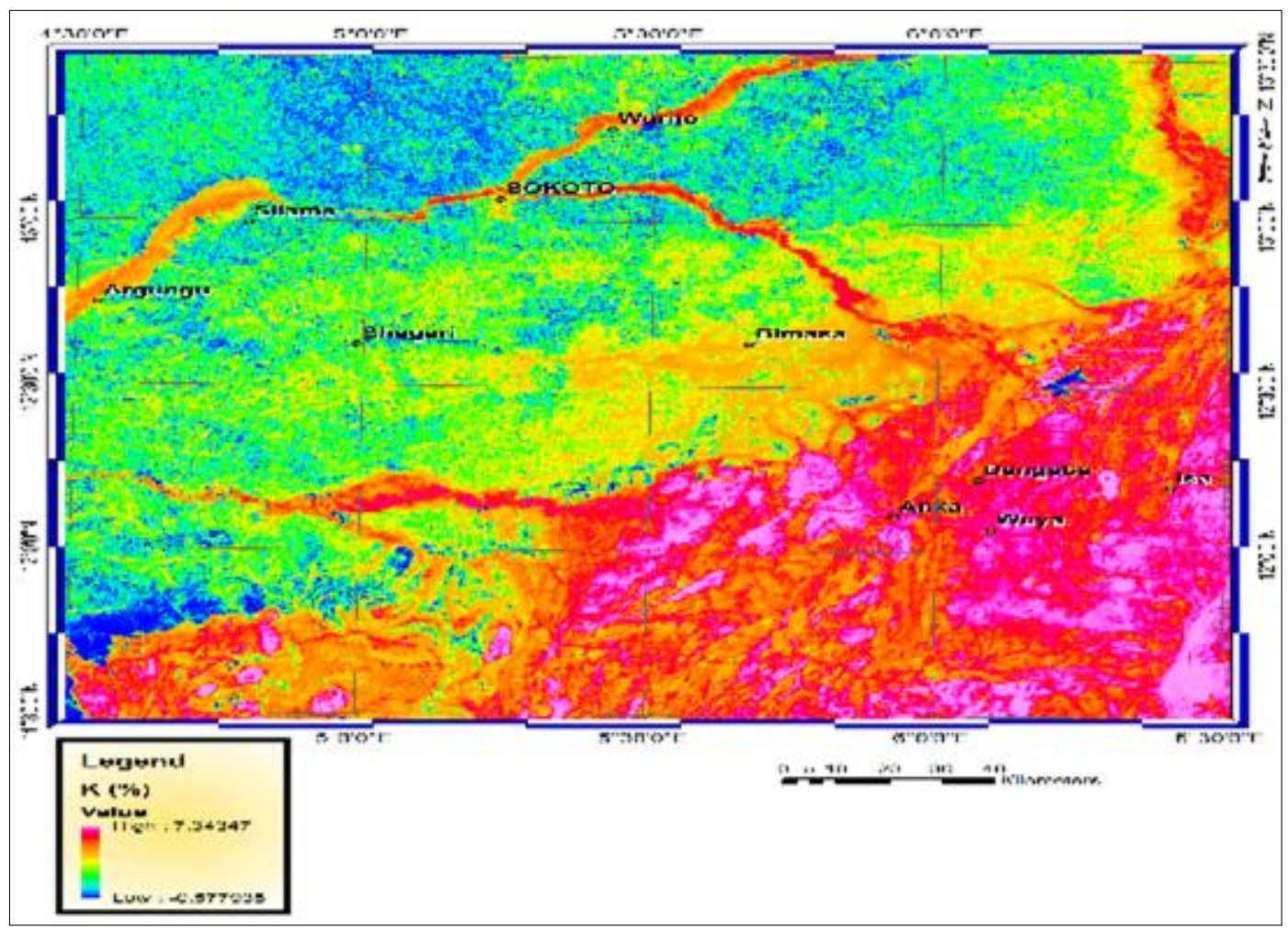

Figure 3 map of pottassium $\mathrm{K}(\%)$ concentration of the study 
The Potassium K (\%) contour map fig. 3 revealed lowest concentration of $\mathrm{K}(\%)$ in the potential study area as $0.577935 \%$ which is represented with blue colour. This is seen at the northern region and scanty at the northwestern zones of the potential study area. The moderate level of concentration is revealed at the northeastern, western and scanty at the south and southwestern parts of the area as represented with yellow colour. The highest concentration $(7.34347 \%)$ was revealed at the south and southeastern regions of the potential study area, represented with pink and red colours. The average value is $3.3827 \%$.

The thorium concentration contour map (fig.4) revealed lowest concentration level as -3.81541 ppm with blue colour and very scanty in the study area. Moderately concentration was seen in major parts of the study area with green and yellow colours. The highest concentration was seen at the southeastern part of the study area with value of $91.9404 \mathrm{ppm}$ represented with pink and red colours. The average value is $44.0624 \mathrm{ppm}$.

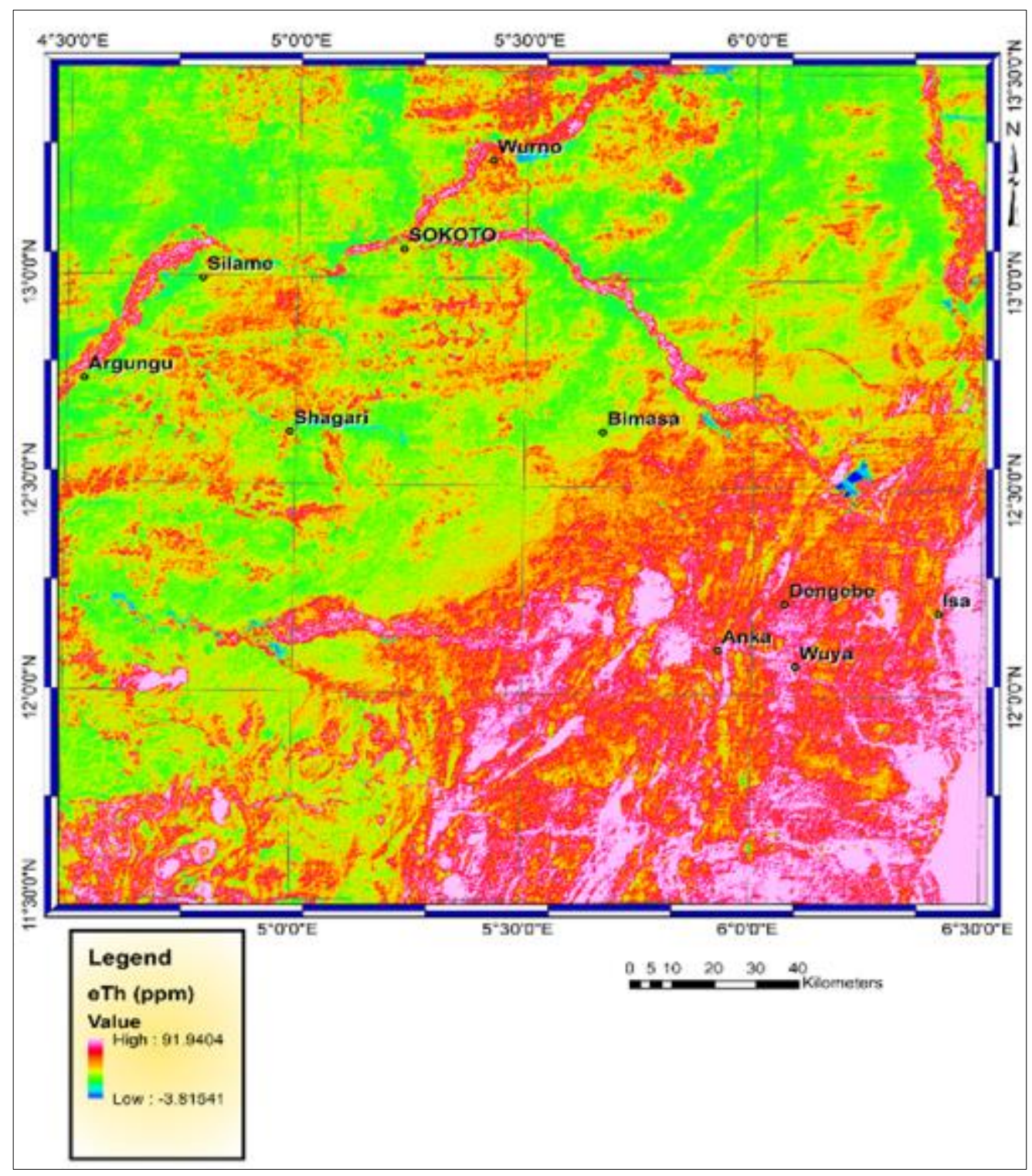

Figure 4 Map Of Thorium Concentration Of The Study Area

The Uranium concentration contour map (fig.5) revealed high value of 46.1767 with red and pink colours, this is seen at the northwestern and southeastern parts of the study area. The lowest concentration represented with blue colour is seen very scanty in the study area. The study area is dominantly concentrated with moderate uranium concentration as represented with yellow and green colours. The average value is $20.86572 \mathrm{ppm}$. 


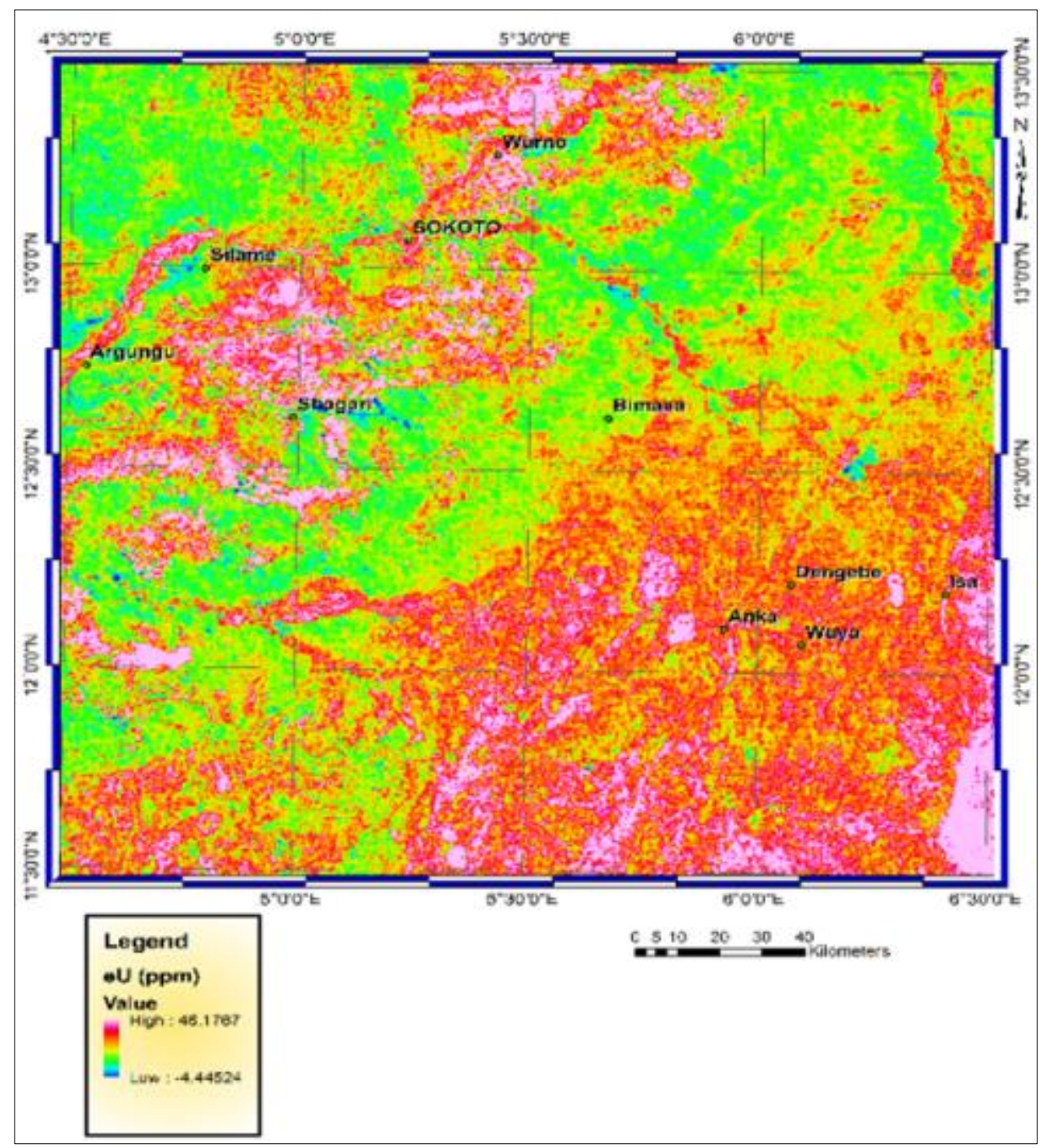

Figure 5 Map Of Uranium Concentration Of The Study Area

From the contour map of Potassium and Thorium concentration ratio (fig. 6), Potassium K (\%) was seen to more mobile than Thorium. The highest value is $39.507 \% / \mathrm{ppm}$, represented with pink colour and the lowest value is $8.69847 \% / p p m$ represented with blue colour. The high concentration (anomaly) was revealed at the southeastern parts through south parts of the study area and were distinguished to areas of geothermal alteration which can be characterized by Potassium enrichment. Moreover, relying on the assumption that K/Th is rather constant in most rocks, the values ranging from -8.69847 to $39,507 \% / \mathrm{ppm}$. Rocks having values varying outside this range for K/Th ratios have been considered $\mathrm{K}$ or Th specialized [18]. The zones characterized with high value of $\mathrm{K} / \mathrm{eTh}$ ratio are strong indicators of geothermal alteration while the zones with low values of K/eTh ratio are strong indicators of low geothermal activities.

The contour map of eU/eTh ratio (fig. 7) revealed that the radioactive level of eTh was higher than that of eU. eU/eTh ratio dominates the western and northwestern parts of the study area with the highest value at the western part of the study area as represented with pink colour. Majority of the study area is dominated with moderate concentration of $\mathrm{eU} / \mathrm{eTh}$ ratio as represented with yellow colour. The lowest concentration is seen at the eastern part of the study area with the value $-412.181 \mathrm{ppm}$ and is represented with blue colour.

The ternary map (fig. 8) was produced by modulating three colours red, green and blue for the intensities of Potassium, Thorium and Uranium respectively. The radiometric response in the ternary map to some extent corresponded with the surface rock units' values of the potential study area and showed a closed spatial correlation with the litho-units. The visual inspection of the radiometric maps showed high concentration of Potassium K (\%), Thorium (eTh) and Uranium (eU) radioactive elements in a lighter colours and were distinguished by their strong radiometric response and which can be easily differentiated from the low radioactive rocks. The low concentration of $\mathrm{K}$, eTh and eU 
radioactive elements were represented by dark colours. From the ternary map, the blue colour represents high eU content but low $\mathrm{K}$ and eTh. The green colour represents high eTh with low $\mathrm{K}$ and $\mathrm{eU}$. The red colour corresponds to high $\mathrm{K}$ with low eU and eTh.

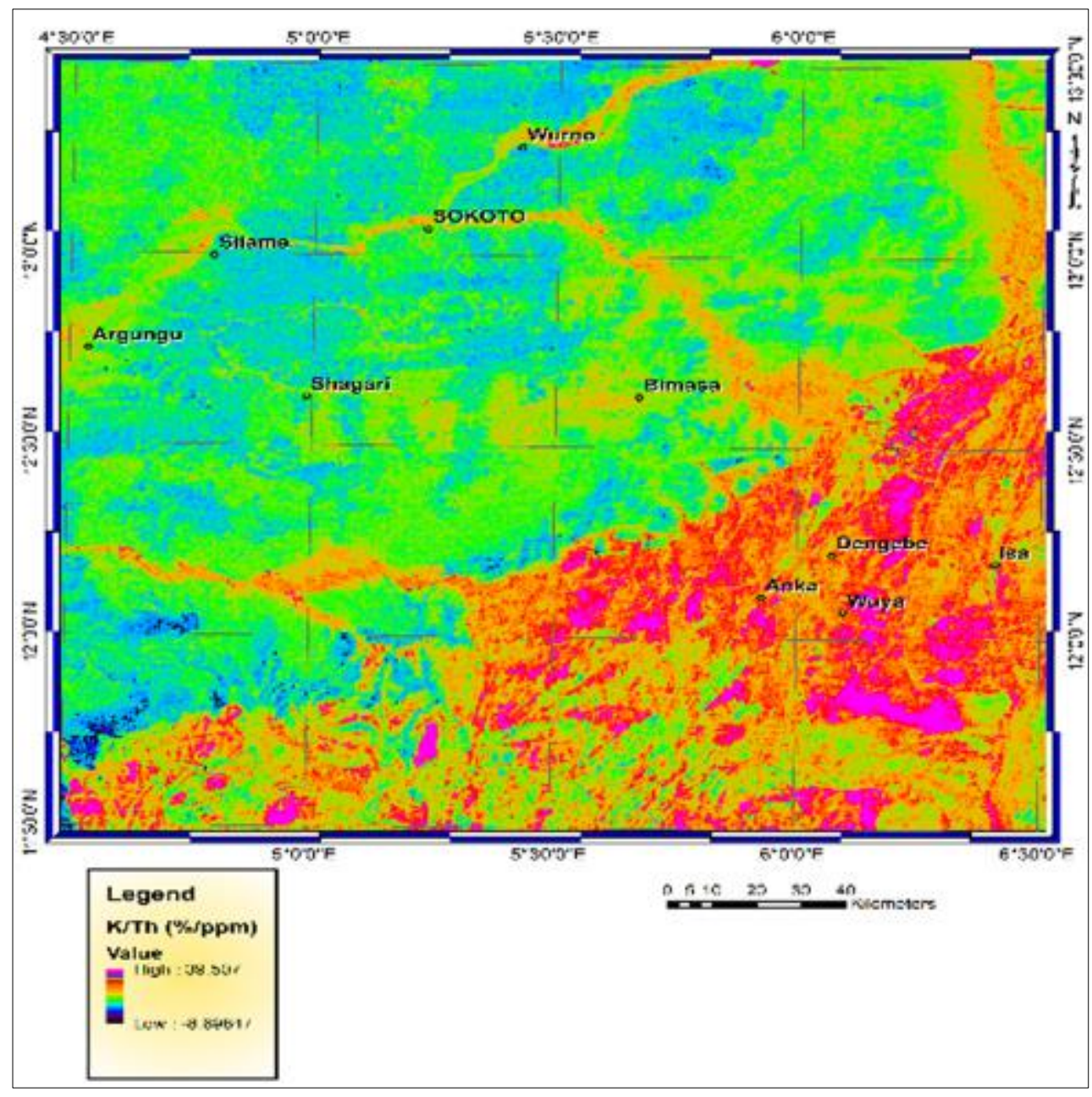

Figure 6 Map Of K/Th Concentration Of The

Airborne radiometric data covering the study area was used to show the distribution and intensities of K(\%), eTh and eU. The Thorium-232, Uranium-238 decay series as well as Potassium-40 were the natural radionuclides that were used for estimation of equivalent Thorium (eTh), equivalent Uranium (eU) and Potassium $\mathrm{K}(\%)$ in the airborne radiometric study. The south and southeastern parts of the study area have high concentration of Potassium, Thorium and Uranium radioactive elements and this is attributed to high heat flow and high geothermal gradient of the basin which affects hydrocarbon accumulation in the Sokoto basin [19] [20] [21].

The average value of eU in the potential study area is $20.86573 \mathrm{ppm}$ ranging from -4.44524 to $46.1767 \mathrm{ppm}$ and the average value of eU in a natural environment is between 2-3ppm [5]. The average value of $\mathrm{K}(\%)$ in the potential study is found to be 3.3827 having a minimum value of $-0.579935 \%$ and a maximum value of $7.343407 \%$ and the average value of $\mathrm{K}(\%)$ in a natural environment is between $2-2.5 \%$ [5]. The equivalent Thorium concentration (eTh) has an average value of $44.0624 \mathrm{ppm}$ with minimum value of $-3.81541 \mathrm{ppm}$ and maximum value of $91.9404 \mathrm{ppm}$ and the average value of eTh in a natural environment is between $8-12 \mathrm{ppm}$ [5]. Thorium had the highest radioactive content, followed by Uranium and the lowest content is Potassium. 


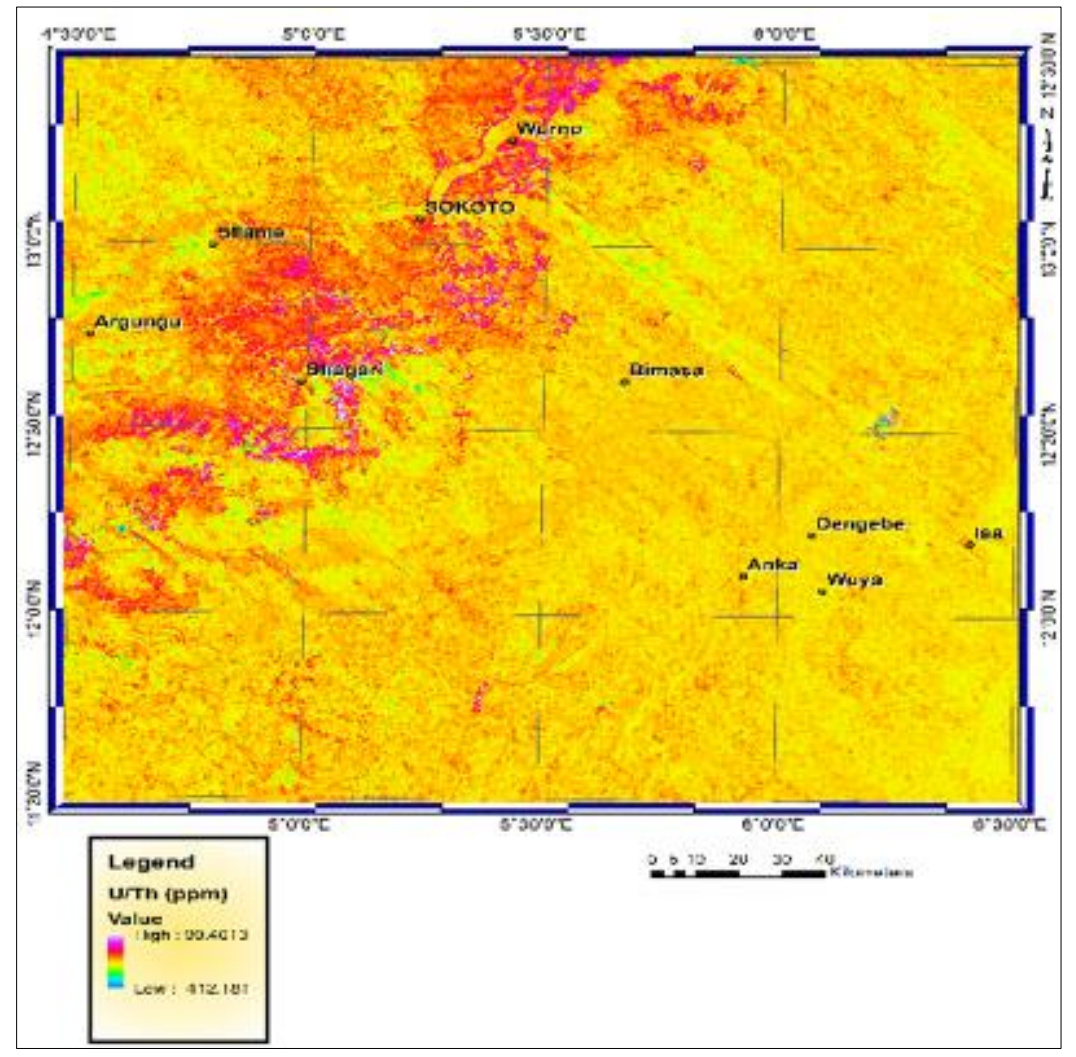

Figure 7 Map Of U/Th Concentration Of The Study Area

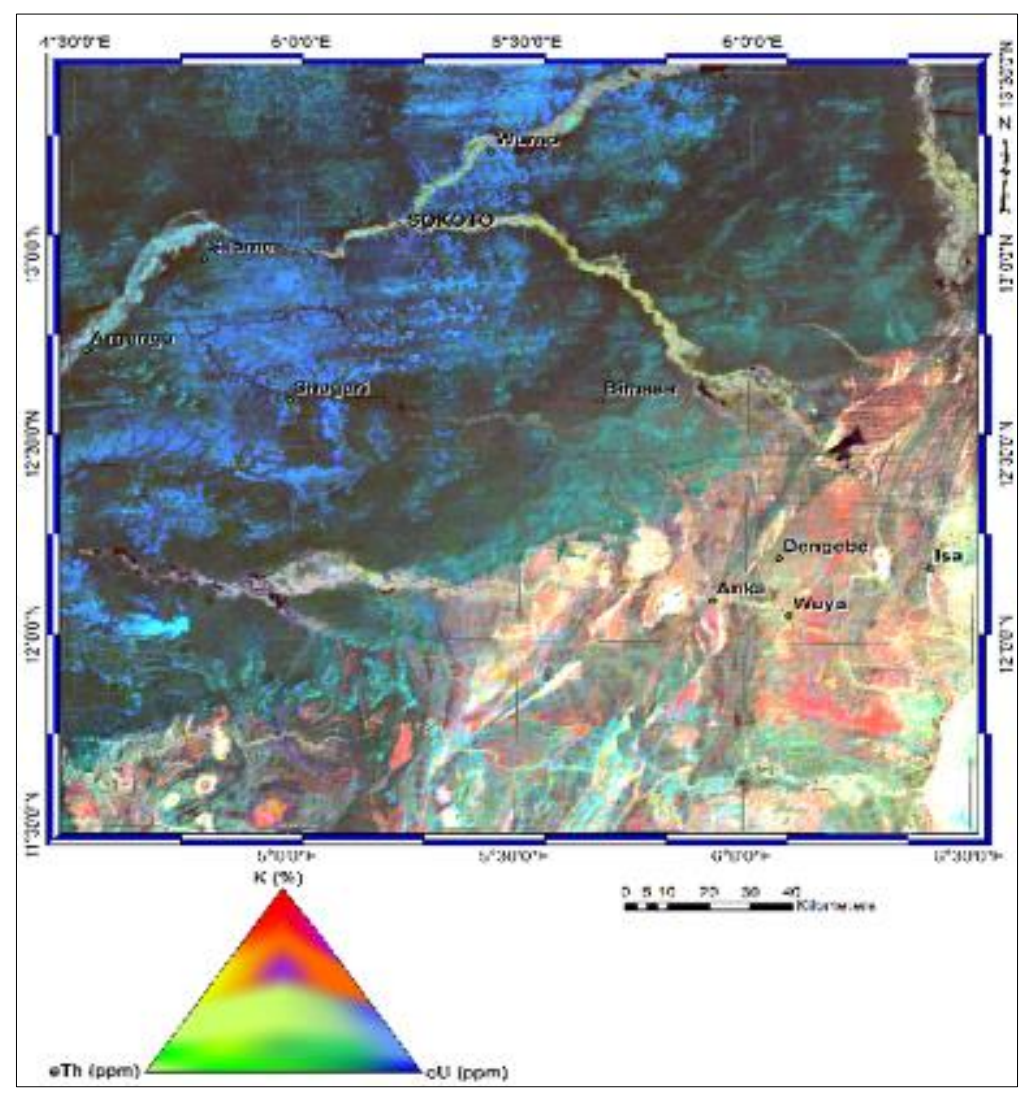

Figure 8 Ternary Diagram of Radioactive Elements 
The Precambrian basement complex is enriched in Thorium and Uranium concentration due to Shale content, organic and Phosphatic materials and little Potassium. Low percentage of Potassium and Thorium were recorded in Gwadu Formation (fig. 8). The radioactive isotopes as a sources of geothermal energy have played a role in the high heat flow of the basin which is one of the reasons the basin has not produced hydrocarbon.

\section{Conclusion}

The radiometric analysis has revealed the existence of high concentration of $\mathrm{K}(\%)$, eTh and eU in the study area with thorium having the highest concentration. The average crustal abundance of radioactive isotopes has shown that the potential study area has high average crustal abundance above normal environment and has contributed to the high heat flow and geothermal gradient since radioactive isotopes are one of the geothermal energy sources.

\section{Compliance with ethical standards}

\section{Acknowledgments}

I sincerely acknowledge Nigerian Geological Survey Agency (NGSA) for making the radiometric data available for this research work.

\section{Disclosure of conflict of interest}

No conflict of interest. As this is the contribution of the aforementioned authors.

\section{References}

[1] Abraham EM, Lawal KM, Ekwe AC, Alile 0, Lawal AA. Spectral Analysis of Aeromagnetic Data for Geothermal Energy Investigation of Ikogosi Warm Spring - Ekiti State, Southwestern Nigeria. Geothermal Energy. $2014 ; 2: 6$.

[2] Abraham EM, Nkitnam EE. Review of Geothermal Energy Research in Nigeria. The Geoscience Front. International Journal of Earth Science and Geophysics. (IJESG). 2017; 3(15): 1-10.

[3] Ayuba RA, Nur A. Determination of Curie Depth Isotherm and Geothermal Studies over Parts of Nasarawa and Environs, North Central Nigeria. International Journal of Energy and Environmental Science. 2018; 3(4): 69-81.

[4] Olumide AJ, Ewa K, Shoeneich K, Enoch AI. Geothermal Gradient of the Niger Delta from Recent Studies. IJSER. $2013 ; 4(11)$.

[5] Ramadass G, Subhah BG, Lakmi U. Structural Analysis of Airborne Radiometric Data for Identification of Kimberlites in Parts of Eastern Dharwar Craton. Int.Journal of Science and Research (IJSR). 2015; 4(4): 23752380.

[6] Telford WM, Geldart LP, Sheriff RE. Applied Geophysics. 2nd Edition, Cambridge university press. 1990.

[7] Adams JAS. Radiometric Determination of Thorium, Uranium, and Potassium in the Field: GSA Special. Paper. 1961; 68: 125.

[8] Paul AC, Pillai PMB, Velayudhan T, Pillai KC. Internal Exposure at High Background Areas. In: Proc. Inter. Symp. On Natural Radiation Environment, Bombay, India. Wiley Eastern Ltd., BARC. 1982; 50.

[9] Wilford JR, Bierwirth PN, Craig MA. Application of Airborne Gamma-Ray Spectrometry in Soil/ Regolith Mapping and Applied Geomorphology. AGSO J. Austr. Geol. Geophys. 1997; 17: 201-216.

[10] Adams JAS, Gasparini P. Gamma Ray Spectrometry of Rocks. New York: Elsevier. 1970; 295.

[11] Iyengar MAR, Rajan MP, Ganapathy S, Kamath PR. Sources of Natural Radiation Exposure in a Low Monazite Environment. In: Natural Radiation Environment. - III, T.F. Gesell and W.M. Lowder (Eds), Proc. Of the Symp. On Natural Radiation Environment, Houston, TX, USAEG. 1980; CONF-780422: 1090.

[12] Mohanty AK, Sengupta D, Das SK, Vijayan V, Saha SK. Natural Radioactivity in the Newly Discovered High Background Radiation Area on the Eastern Coast of Orissa, India. Rad. Meas. 2004; 38: 153-165.

[13] Blum M de LB, Moraes RAV, Pires ACB, Jost H. Caracterização dos Complexos Ortognássicos Arqueanos de Goiás por Meio de Gamaespectrometria Aérea. Revista Brasileira de Geociências, S. Paulo. 2003; 33(2): 147-152. 
[14] Holmberg H, Naess E, Evensen JE. Thermal Modeling in the Oslo rift. In: Norway. Proceedings, 37th workshop on geothermal reservoir engineering, Stanford University. 2012.

[15] Rybach K. Equation for Radiogenic Heat Production. In: An Introduction to Geophysical Exploration. Philip A0, McGraw Hill, New York. 1988.

[16] Masters G, Constable S. Introduction to Geophysics. Institute of Geophysics and Planetary Physics. 2013.

[17] Mandel A, Mohanty WK, Sharma SP, Biswas A, Sen J, Bhatt AK. Geophysical Signatures of Uranium Mineralization and its Subsurface Validation at Beldih, Purulia District, West Bengal, India: A Case Study. Geophysical prospecting. 2015; 63: 713-726.

[18] Elkhateeb SO, Abdellatif MAG. Delineation Potential Gold Mineralization Zones in a Part of Central Eastern Desert, Egypt Using Airborne Magnetic and Radiometric data.NRIAG Journal of Astronomy and Geophysics. 2018; 7(2).

[19] Jessop AM, Habart MA, Sclater JC. The World Heat Flow Data Collection, 1975 Geothermal Service of Canada. Geothermal Services. 1976; 50: 55-77.

[20] Wright JB, Hasting D, Jones WB, Willian HR. Geology and Mineral Resources of West Africa. Geological, Journal. $1985 ; 22: 211-212$.

[21] Oghuma AA, Obiadi H, Obiadi CM. 2D Spectral Analysis of Aeromagnetic Anomalies Over Parts of Monguno and Environs, Northeastern Nigeria. Journal of Earth Science \$ Climatic Change. 2015; 6(8): 1-6. 